\title{
Processing Carbon Rod from Waste of Zing-Carbon Battery for Biogas Desulfurizer
}

\author{
Tjokorda Gde Tirta Nindhia, I. Wayan Surata, I. Ketut Adi Atmika, Dewa Ngakan Ketut Putra Negara, \\ and I. Putu Gede Artana
}

\begin{abstract}
The carbon rod of used zinc-carbon battery was investigated in this research to be recycled as biogas desulfurizer. The carbon rod was taken out from the used battery and crushed to become a pellet with about $1 \mathrm{~cm}$ long. To increase its performance, the carbon rod was put in solution of $\mathrm{KMnO}_{4}$ and water then tested its performance as desulfurizer. It is found that the performance of desulfurizer increase by putting about 200 gram of carbon rod in the solution of $\mathrm{KMnO}_{4}$ with minimum concentration of 20 gram $\mathrm{KMnO} 4$ /liter water. It is suggested during application to use low flow rate of biogas (around 1-3 liters/minute) to achieve maximum performance.
\end{abstract}

Index Terms-Carbon rod, zinc-carbon, battery, biogas, desulfurizer, performance.

\section{INTRODUCTION}

Biogas is a very important source of renewable methane which is deriving from biomass sources and has great potential for growth to meet future energy demands. Biogas is produced from anaerobic biodegradation of biomass in the absence of oxygen and the presence of anaerobic microorganisms [1].

Anaerobic digestion is a series of metabolic interactions of microorganisms. The process is carried out in digesters at temperatures ranging from 30 to $65{ }^{\circ} \mathrm{C}$ [2]. Anaerobic digesters are typically designed to operate in the mesophilic $\left(20-40{ }^{\circ} \mathrm{C}\right.$ ) or thermophilic (above $40^{\circ} \mathrm{C}$ ) temperature zones. Sludge produced from the anaerobic digestion is often used as a fertilizer. Biogas recovery technologies have been failures in many developing countries, with low rates of technology transfer and longevity and a reputation for being difficult to operate and maintain. Designs which deliver lower cost, improved robustness, functionality, ease of construction, operation and maintenance would aid the market penetration of biogas plan [2].

There is greater potential for biogas as a transport vehicle fuel. Biogas may be compressed in gas cylinders or transportable via pipelines. This is possible only after removing hydrogen sulfide $\left(\mathrm{H}_{2} \mathrm{~S}\right)[1]$. Hydrogen sulfide $\left(\mathrm{H}_{2} \mathrm{~S}\right)$ is contaminant in biogas and other S-containing compounds that come from $\mathrm{S}$-bearing organic matters which is depending

Manuscript received January 31, 2014; revised May 5, 2014. This work was supported financially by the Ministry of Education Culture, The Republic of Indonesia through second phase scheme of competitive research grant (skim penelitian hibah bersaing) for the year of 2014 granted through Udayana University, Jimbaran, Bali, Indonesia

The authors are with the Department of Mechanical Engineering, Engineering Faculty, Udayana University Jimbaran, Bali, Indonesia, 80361 (e-mail: nindhia@yahoo.com). on the composition of the organic matter. The $\mathrm{H}_{2} \mathrm{~S}$ content in biogas vary from 100 to $10.000 \mathrm{ppm}$. This contaminant is undesirable in combustion systems due to its conversion to highly corrosive and environmentally hazardous compounds. It is essential to remove before any further utilization of biogas [1], [3], [4]. Hydrogen sulfide is a pollutant that is commonly regarded as toxic. Inhalation of high concentrations of hydrogen sulfide can be lethal. Hydrogen sulfide mainly attacks the neural system and important organs, like the liver and the kidney [5].

Together with $\mathrm{CH}_{4}$ in the biogas, $\mathrm{H}_{2} \mathrm{~S}$ burns in engines, and it exhausts in the form of $\mathrm{SO}_{2}$ which is more dangerous than $\mathrm{H}_{2} \mathrm{~S}$ as it is hazardous for health and environment such as smog and acid rain. Several small scale plants and projects using biogas have ended because of the corrosion problem of $\mathrm{H}_{2} \mathrm{~S}$. Owing to the potential problems that $\mathrm{H}_{2} \mathrm{~S}$ can cause, it is necessary to remove it prior to its use as stable product, at least as a solid residue that can be disposed off easily and safely [6].

Due to the damage that $\mathrm{H}_{2} \mathrm{~S}$ can cause in piping and motors, it is typically removed in an early state of the biogas upgrading process. Several techniques are applied: (1) removal of $\mathrm{H}_{2} \mathrm{~S}$ during digestion and (2) removal of $\mathrm{H}_{2} \mathrm{~S}$ after digestion [7].

During digestion, removal of $\mathrm{H}_{2} \mathrm{~S}$ can be done by dosing air of oxygen in to digester of by adding iron chloride into the digester. Meanwhile $\mathrm{H}_{2} \mathrm{~S}$ can be removed after digestion by using several techniques such as adsorbsion, biological filter or membrane separation. Adsorption can be carried out by using Iron oxide, liquid, or activated carbon [7].

Adsorption in generally is understood as surface based adhesion (molecules, atoms ions or dissolved solid) to a surface and create process a film on the surface of the adsorbent. Commercially adsorbents are usually in the form of particulate (spherical, rods, moldings, or monoliths) is designed having small pore diameters, which yield higher exposed surface area for high surface capacity of adsorption. By using adsorption process, the $\mathrm{H}_{2} \mathrm{~S}$ contaminant in the biogas can be removed. Some natural material such as zeolite [8] and activated carbon [9] were recognized as successful desulfurizer for biogas.

Activated carbons are the adsorbents with the most favorable characteristics for natural gas storage, because they have a large microporous volume, are efficiently compacted into a packed [9].

Activated carbon is characterized by highly porous, amorphous solid. It is available in small pellets or a powder. Activated carbon is produced from carbonaceous material. The manufacturing process consists of two steps, 
carbonization and activation. The carbonization process includes drying and then heating to separate with tars and other hydrocarbons of any gases generated. The carbonized particles are then activated by exposing them to an oxidizing agent such as KI or usually steam at high temperature [10]. This agent eliminated pore blocking structures created during the carbonization phase and so they develop a porous structure.

A source of carbon active such as made from bituminous was found success to be used as desulfurizer by using various chemical treatments, such as nitric acid (HNO) oxidation, metal $(\mathrm{Zn}$ and $\mathrm{Cu})$ impregnation, and thermal desorption of oxygen functional groups [11].

Carbon-based sorbents have been evaluated for the removal of hydrogen sulfide. It is concluded that the surface area and pore volume are not the only factors contributing to $\mathrm{H} 2 \mathrm{~S}$ adsorption, and that surface chemistry played a significant role in the uptake of $\mathrm{H}_{2} \mathrm{~S}$ [5].

The zinc-carbon battery consist of zinc case as a container and negative terminal, carbon road as positive terminal and mixture of $\mathrm{MnO}_{2}$, graphite powder and ammonium chloride as electrolyte as can be seen in Fig. 1. After used or spent, the carbon rod is still remain and possible to be recycled again.

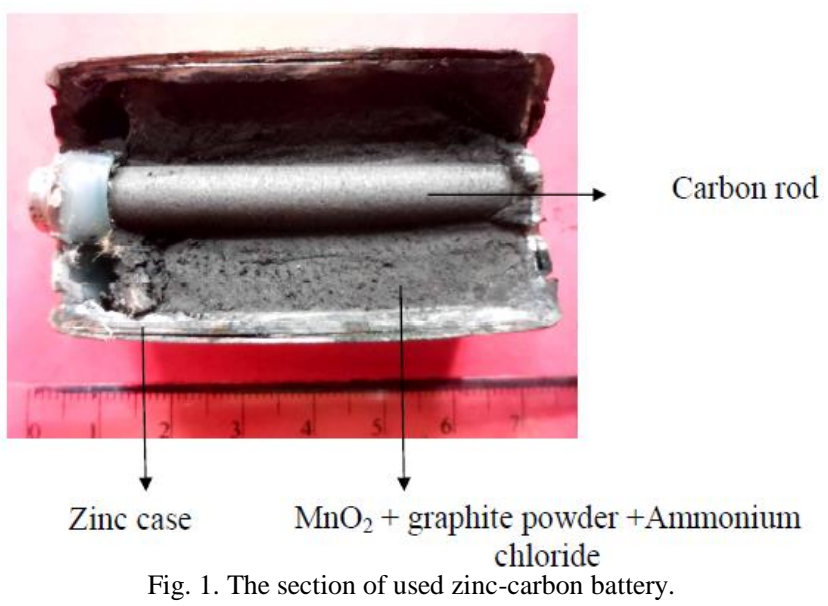

In the case of type battery waste in Japan, it can be found that the production and consumption of zinc- carbon battery in the top position among other types of battery. But from the general overview of battery waste management in Japan [12], the carbon rod from the waste of used zinc-carbon battery was not take in to consideration for recycle or reuse.

The zinc-carbon battery is the most popular source of portable electrical energy. More than 300000 tons of batteries are sold yearly worldwide. It is a challenge to achieve the recycling of consumer-type batteries. Individuals should cooperate in such a program in order to ensure its success. Basic on energy balance of the chemical active part of the battery, the value and supply of the material and finally the steps and alternative route to the recycling of zinc-carbon batteries, it is necessary or useful to recycle zinc batteries [13]

This article introduces successful work on the effort of recycling carbon rod from used zinc-carbon battery as desulfurizer for biogas purification. The simultaneous solving problems of battery waste and harmful gas of $\mathrm{H}_{2} \mathrm{~S}$ in the biogas can be solved by technique that is explained in this article.

\section{EXPERIMENTAL}

The carbon rod from the used zinc-carbon battery was taken out by easy pulling it from the body of the battery as depicted in Fig. 2. The carbon rod then was crushed in about 1 $\mathrm{cm}$ long as can be seen in Fig. 3. The catalyst that was selected to increase adsorption rate of $\mathrm{H}_{2} \mathrm{~S}$ on the carbon rod was $\mathrm{KMnO}_{4}$. The research is divided in to 2 parts. First was to investigate the effect of concentration variation of $\mathrm{KMnO}_{4}$ in water in which the carbon rod is put in to incrase its performance as desulfurizer. For this purpose 200 gram of crushed carbon rod was put in six variations of concentrations of $\mathrm{KMnO}_{4}$ namely: 0, 20, 40, 60, 80, 100 gram in one liter of water for 24 hours. The performance of carbon rod as desulfurizer then was investigate by following schematic that is presented in Fig. 4.

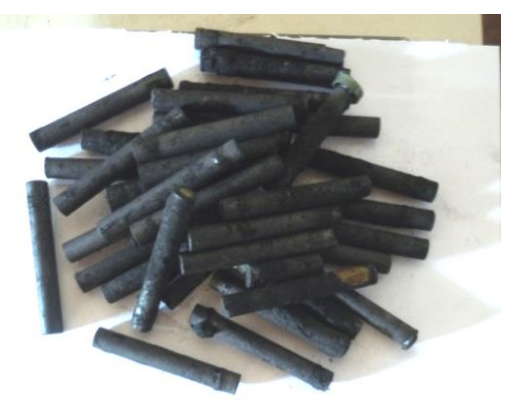

Fig. 2. Carbon rod obtained from used zinc-carbon batteries.

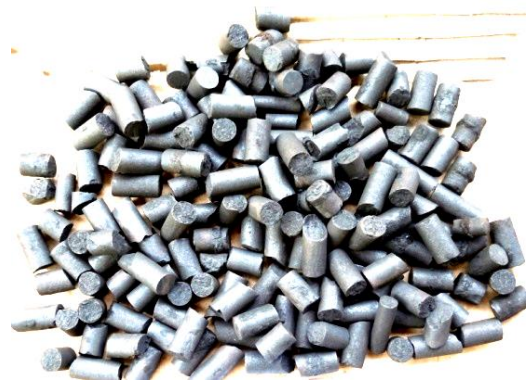

Fig. 3. Carbon rod was crushed in to about $1 \mathrm{~cm}$ long.

The system was arranged with flow rate about 3 liters/minute. The performance of desulfurizer was evaluated by measuring the $\mathrm{H}_{2} \mathrm{~S}$ contents in the biogas before and after passing the desulfurizer as can be seen in Fig. 4. The biogas was let flow from gas container 1 with flow rate was controlled by using valve 2 . The flow rate was checked by using flow rate indicator 3 . To measure the $\mathrm{H}_{2} \mathrm{~S}$ contents in the biogas before entering desulfurizer, the valve 4 was closed and the valve 5 was opened and let the biogas flow to the $\mathrm{H}_{2} \mathrm{~S}$ gas sensor 6 . If the desulfurizer working well, then the $\mathrm{H}_{2} \mathrm{~S}$ contents in the biogas will decrease and can be measured by closing valve 8 and open the valve 9 and let the biogas flow to the $\mathrm{H}_{2} \mathrm{~S}$ gas sensor 10 . The performance of desulfurizer then can be calculated by using Equation 1. The performance of desulfurizer was measured for 5 liters of biogas that passed the desulfurizer with 3 time repetition. The averages of desulfurizer performance then will be calculated and presented in form of graph for analyzed.

$$
\frac{\mathrm{H}_{2} \mathrm{~S} \text { before desulfurizer }-\mathrm{H}_{2} \mathrm{~S} \text { after desulfurizer }}{\mathrm{H}_{2} \mathrm{~S} \text { before desulfurizer }} \times 100 \%
$$




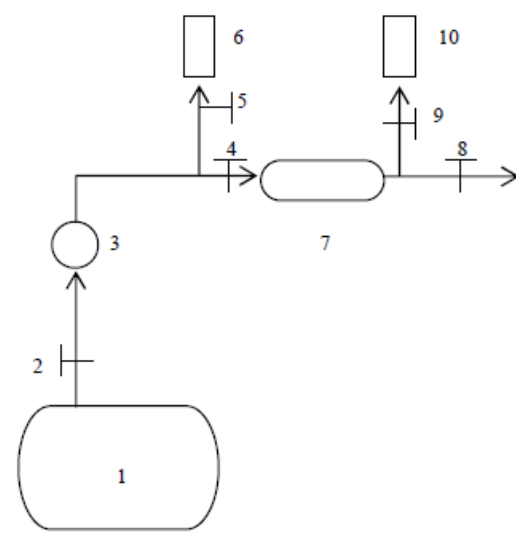

Fig. 4. Schematic of experiment for desulfurizer test performance: 1. Biogas container, 2.Valve, 3.Flow rate indicator, 4. Valve, 5. valve, $6 . \mathrm{H}_{2} \mathrm{~S}$ gas sensor, 7. Desulfurizer, 8. Valve, 9.valve, $10 . \mathrm{H}_{2} \mathrm{~S}$ gas sensor.

The second investigation was to understand the effect of flow rate of the biogas to the performance of desufurizer made from carbon rod of used zinc-carbon battery. For this purpose there were 5 variations of the biogas flow rate namely: 1, 2, 3, 4 ,and 5 liters/minute, and it was prepared 5 desefurizer for this purpose that were made from 200 gram of carbon rod of used zinc-carbon battery. The desulfurizers were put in the solution of 20 gram $\mathrm{KMnO}_{4}$ in 1 liter of water for 24 hours. The performances then were investigated by using schematic in Fig. 4 and calculated by using Equation 1.

\section{RESULT AND DISCUSSION}

Carbon rod from used zinc-carbon battery can be used directly as desulfurizer but its performance is not optimal as can be seen in the graph of Fig. 5. The performances just reach up to $81.21 \%$ of $\mathrm{H}_{2} \mathrm{~S}$ elimination. This is due to only reaction between carbon $(\mathrm{C})$ and $\mathrm{H}_{2} \mathrm{~S}$ that occurring base on Equation 2 [5], [11].

$$
\mathrm{C}+\mathrm{H}_{2} \mathrm{~S} \rightarrow \mathrm{C}-\mathrm{S}+\mathrm{H}_{2}
$$

By putting the desulfurizer in the solution of 20 gram $\mathrm{KMnO}_{4}$ in 1 liter water for 24 hour the performance of desulfurizer increase and reach optimum performance of $100 \%$ of $\mathrm{H}_{2} \mathrm{~S}$ elimination from the biogas as can be seen in Fig 5. This is due to not only reaction in Equation 2 that occur but also involving reaction of carbon $(\mathrm{C})$ and oxygen $(\mathrm{O})$ from $\mathrm{KMnO}_{4}$ as reaction in the Equation 3 bellow [5], [11]:

$$
\mathrm{C}-\mathrm{O}+\mathrm{H}_{2} \mathrm{~S} \rightarrow \mathrm{C}-\mathrm{S}+\mathrm{H}_{2}
$$

The performance of desulfurizer is not decrease by addition of concentration $\mathrm{KMnO}_{4}$ more than 20 gram of 1 liter of water as can be seen from Fig. 5. The performance is still in optimum value with addition until 100 gram of $\mathrm{KMnO}_{4}$ in 1 liter of water.

Increasing performance of carbon desulfurizer by using $\mathrm{KMnO} 4$ that is introduced in this research is found more practical comparing by using $\mathrm{KI}$ or $\mathrm{H}_{2} \mathrm{SO}_{4}$ as informed in previous publication [7] because no need addition of air as a source of oxygen in other reaction in the Equation 3 to occur.

$$
2 \mathrm{H}_{2} \mathrm{~S}+\mathrm{O}_{2} \rightarrow 2 \mathrm{~S}+2 \mathrm{H}_{2} \mathrm{O}
$$

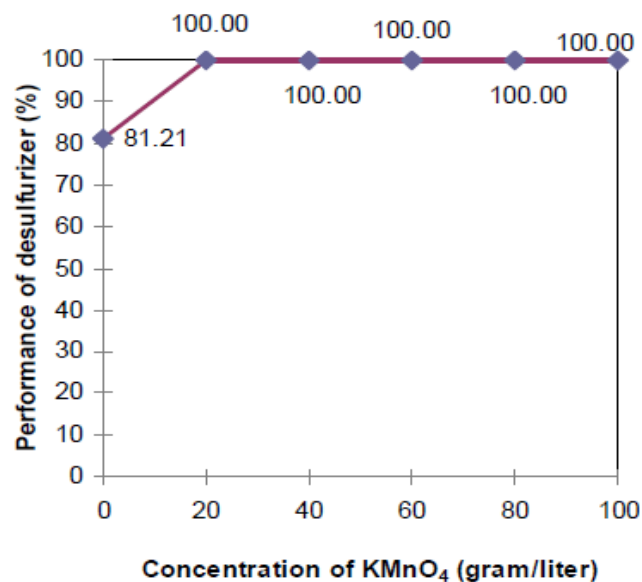

Fig. 5. Effect of $\mathrm{KMnO}_{4}$ concentration on desulfurizer performance.

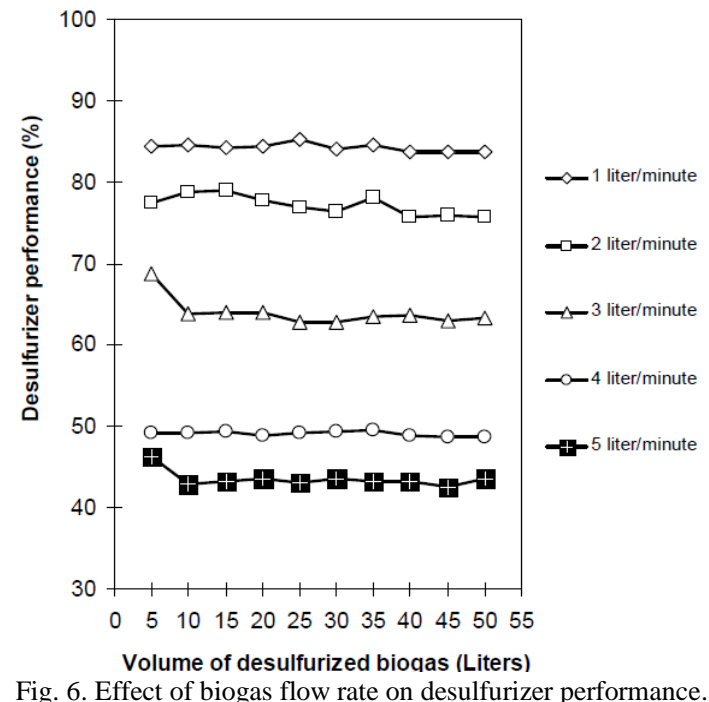

For the use in application, it is good to understand the effect of flow rate of biogas to the performance of the desulfurizer that is made from the carbon rod of zinc-carbon battery. The result is presented in Fig. 6. It is found that better performance is obtained for the low level of flow rate (around 1-3 liters/minute) of the biogas. Increase the flow rate of the biogas is found decrease the performance of the desulfurizer.

\section{CONCLUSIONS}

The carbon rod from waste of zinc-carbon battery is potential to be recycled as desulfurizer of biogas. The carbon rod can be directly use as desulfurizer. In order to increase the performance of the desulfurizer, the carbon rod can be processed by putting in the solution of $\mathrm{KMnO}_{4}$ with concentration minimum 20 gram $\mathrm{KMnO}_{4}$ in 1 liter water. It is suggested during application to use low level of flow rate of the biogas (around 1-3 liters/minute) to achieve best performance of desulfurizer.

\section{ACKNOWLEDGMENT}

The authors wish to thanks the Ministry of National and Culture of The Republic of Indonesia for financial support under scheme of competitive research grant (skim penelitian hibah bersaing) No. 26A/UN.14/PNL.01.03.00/2014, for the year of 2014 granted through Udayana University, Jimbaran, Bali, Indonesia. 


\section{REFERENCES}

[1] N. Tippayawong and P. Thanompongchart, "Biogas quality upgrade by simultaneous removal of $\mathrm{CO}_{2}$ and $\mathrm{H}_{2} \mathrm{~S}$ in a packed column reactor,' Energy, vol. 35, pp. 4531-4535, May 2010.

[2] T. Bond and M. R. Templeton, "History and future of domestic biogas plants in the developing world," Energy for Sustainable Development, vol. 15, pp. 347-354, 2011.

[3] L. V. A. Truong and N. Abatzoglou, "A $\mathrm{H}_{2} \mathrm{~S}$ reactive adsorption process for the purification of biogas prior to its use as a bioenergy vector," Biomass and Bioenergy, vol. 29, pp. 142-151, 2005.

[4] A. B. Baspinar, M. Turker, A. Hocalar, and I. Ozturk, "Biogas desulphurization at technical scale by lithotrophic denitrification: Integration of sulphide and nitrogen removal," Process Biochemistry, vol. 46, pp. 916-922, January, 2011.

[5] W. Feng, S. Kwon, E. Borguet, and R. Vidic, "Adsorption of hydrogen sulfide onto activated carbon fibers: Effect of pore structure and surface chemistry," Environ. Sci. Technol, vol. 39, pp. 9744-9749, November 2005.

[6] J. S. Lar and L. Xiujin, "Removal of H2S during Anaerobic Bioconversion of Dairy Manure," Bioterchnology and Bioengineering, vol. 17, pp. 273-277, 2009.

[7] E. Ryckebosch, M. Drouillon, and H. Vervaeren, "Techniques for transformation of biogas to biomethane," Biomass and Bioenergy, vol. 35 pp. 1633-1645, March 2011.

[8] P. Cosoli, M. Ferrone, S. Pricl, and M. Fermeglia, "Hydrogen sulphide removal from biogas by zeolite adsorption," Chemical Engineering Journal, vol. 145, pp. 86-92, July 2008.

[9] I. A. A. C. Esteves, M. S. S. Lopes, P. M. C. Nunes, and J. P. B. Mota, "Adsorption of natural gas and biogas components on activated carbon," Separation and Purification Technology, vol. 62, pp. 281-296, January 2008.

[10] D. Mescia, S. P. Hernandes, A. Conoci, and N. Russo, "MSW landfill biogas desulfurization," International Journal of Hydrogen Energy, vol. 36, pp. 7884-7890, February 2011.

[11] M. P. Cal, B. W. Strickler, A. A. Lizzio, and S. K. Gangwal, "High temperature hydrogen sulfide adsorption on activated Carbon. II. Effects of gas temperature, gas pressure and sorbent regeneration,' Carbon, vol. 38, pp. 1767-1774, 2000.

[12] T. Kanemaru and T. Matsuoka, "General Overview of Battery Wate Management in Japan,” Journal of Power Source, vol. 57, pp. 23-26, 1995.

[13] J. P. Wiaux and J. P. Waefler, "Recycling Zinc Batteries:an Economical Challenge in Consumer Waste," Journal of Power Source, vol. 57, pp. 61-65, 1995.

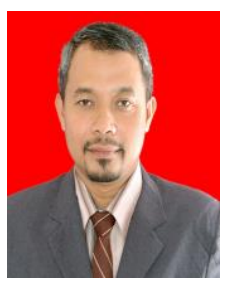

Tjokorda Gde Tirta Nindhia was born in Denpasar, Bali, Indonesia on January $16^{\text {th }}, 1972$. He received doctor degree in mechanical engineering from Gadjah Mada University (UGM) Yogyakarta, Indonesia on August 2003, with major field of study was material engineering.

He participated in various international research collaboration such as with Muroran Institute of Technology Japan (2004), Toyohashi University of
Technology Japan (2006), Leoben Mining University Austria (2008-2009), Technical University of Vienna Austria (2010) and Recently with Institute Chemical Technology of Prague Czech Republic (2012-now). He is currently a full professor in the field of material engineering at Department of Mechanical Engineering, Engineering Faculty, Udayana University, Jimbaran, Bali, Indonesia. His research interest covering subjects such as, biomaterial, waste recycle, failure analyses, ceramic, metallurgy, composite, renewable energy, and environmental friendly manufacturing.

Prof. Nindhia is a member of JICA Alumni, ASEA-UNINET alumni, International Association of Computer Science and Information Technology (IACSIT), Asia-Pacific Chemical, Biological \& Environmental Engineering Society (APCBEES) and also member of association of Indonesian Nanotechnology. Prof Nindhia received best researcher award in 1997 and in 2013 from Udayana University the place where he is working and again in 2012 received both Best lecturer award from Engineering Faculty of Udayana University. In the same years 2012, The research center of Udayana University awarded Prof. Nindhia as the best senior researcher. In 2013 Prof. Nindhia was awarded as 15 best performance Indonesian lecturers from Ministry of Education and Culture The Republic of Indonesia.

I. Wayan Surata was born in Nusa Penida, Bali, Indonesia on July 5, 1958. He received his doctor degree in the field of ergonomic from Udayana University in 2011. His research interest very much related in process of manufacture. His current job is a researcher and lecturer at the Department of Mechanical Engineering, Engineering Faculty, Udayana University, Jimbaran, Bali, Indonesia.

I. Ketut Adi Atmika was born in Negara, Bali, Indonesia on May 18, 1969. He received his master degree in mechanical engineering From Institute Technology of Sepuluh November, Surabaya, Indonesia. His current job is a researcher and lecturer at the Department of Mechanical Engineering, Engineering Faculty, Udayana University, Jimbaran, Bali, Indonesia.

Dewa Ngakan Ketut Putra Negara was born in Payangan, Bali, Indonesia on June 13, 1971. He received M.Sc degree from University of Bradford, UK in 2001 in manufacturing systems engineering and management. His current job is a researcher and lecturer at the Department of Mechanical Engineering, Engineering Faculty, Udayana University, Jimbaran, Bali, Indonesia.

I. Putu Gede Artana was an undergraduate student at the Department of Mechanical Engineering, Udayana University, Jimbaran, Bali, Indonesia and graduated in 2012 . 